\title{
CRÍTICA DE LA RAZÓN PURA DE LA LEY: SOBRE LA SECULARIZACIÓN BÍBLICA EN LA NARRATIVA DE LOS DERECHOS HUMANOS*
}

\author{
CRITIC OF PURE REASON OF THE \\ LAW: SECULARIZATION IN THE \\ NARRATIVE OF THE HUMAN RIGHTS
}

\author{
Luis Ricardo Gómez-Pinto**
}

Fecha de recepción: 13 de agosto de 2014 Fecha de aceptación: 8 de octubre de 2014 Disponible en linea: 30 de junio de 2015

\section{Para citar este artículo/To cite this article}

Gómez-Pinto, Luis Ricardo, Crítica de la razón pura de la ley: sobre la secularización bíblica en la narrativa de los Derechos Humanos, 130 Vniversitas, 179-206 (2015). http://dx.doi.org/10.11144/Javeriana.vj130.crpl

doi:10.11144/Javeriana.vj130.crpl

* Las ideas originales de este texto surgen de las discusiones planteadas en el curso de Antropología Filosófica, bajo la guía del profesor Roberto Solarte, a quien agradezco por sus comentarios e ideas que fueron vitales para los ajustes, todos necesarios, del trabajo final.

** Abogado, Pontificia Universidad Javeriana. Especialista en derecho sustantivo y contencioso constitucional. Magíster en derecho económico. Profesor de constitución económica y derecho económico, Facultad de Ciencias Jurídicas de la Pontificia Universidad Javeriana. Miembro del grupo de investigación de Derecho Público en la misma Facultad. Ha sido profesor de Derecho Constitucional, Universidad Jorge Tadeo Lozano. Actualmente se desempeña como funcionario del Ministerio del Trabajo y es estudiante de la carrera de Filosofía. Contacto: l.gomezp@javeriana.edu.co 


\section{RESUMEN}

De acuerdo a las tesis de Costas Douzinas, los conceptos de ley y derechos humanos resultan ser categorías contradictorias. La ley, en la modernidad, trata de justificar un proyecto de violencia para evitar la ira divina. Los derechos humanos, por su parte, parecen asentarse en una interpretación del mensaje de compasión y caridad del evangelio. La primera es una interpretación ideológica de los textos bíblicos; la segunda, una interpretación más asentada en los cuestionamientos de la antropología filosófica por el ser, la razón del ser y la búsqueda de la verdad.

Este artículo propone, a la luz de los interrogantes de Costas Douzinas y René Girard, entre otros, una lectura que sugiere una respuesta que puede resultar riesgosa a esta contradicción. El riesgo consiste en que la manera de ver la ley como expresión del moderno Estado de derecho entra en crisis. Los procesos de expresión de la violencia moderna advertirán esto. El protagonista detrás del telón que se revela en el escenario del derecho no es la ley, sino la víctima del sacrificio. Esto amenazará la sostenibilidad del derecho como un sistema científico cerrado y coherente.

Palabras clave: secularización; derechos humanos; deseo; violencia; sacrificio; evangelio; René Girard; Costas Douzinas; víctima 


\section{ABSTRACT}

According to the thesis of Costas Douzinas, the concepts of law and human rights are contradictory categories. Law, in modernity, tries to justify a project of violence to avoid divine wrath. Human rights, on the other hand, seem to settle with an interpretation of the message of compassion and charity written in the gospels. The first is an ideological interpretation of the biblical texts, while the second is an interpretation based in greater measure on the questions of the philosophical anthropology on being, the reason for being, and the search for the truth. This article proposes, in light of the questions proposed by Costas Douzinas and René Girard, among others, a reading that suggests an answer which may pose a risk to this contradiction. The risk is that seeing law as an expression of the modern Rule of Law enters into a crisis. The modern processes of expressing violence will notice this. The protagonist behind the curtain revealed in the stage of law is not law itself, but the victim of the sacrifice. This threatens the sustainability of law as a closed and coherent scientific system.

Keywords: secularization; human rights; desire; violence; sacrifice; gospel; René Girard; Costas Douzinas; victim

\section{SUMARIO}

Introducción.- I. La ira vengadora de Dios y la Razón de LA Ley. HerMENÉUTICA SOBRE LA TEORÍA DEL MIEDO.- II. CRÍTICAS A LA DOCTRINA DE LA VIOLENCIA MODERNA: DEL ESTOICISMO A LA TESIS DE LOS DERECHOS HuMANOS.III. Fundamentación de los Derechos Humanos como manifestación DE LA SECULARIZACIÓN... O SOBRE LA DESACRALIZACión DE LA LEY.- IV. El ASCENSO DE LOS ÍDOlOS.- CONCluSiones.- Bibliografía. 


\section{INTRODUCCIÓN}

La figura del sacrificio de la que hablan los textos bíblicos y, con mayor precisión, muchos pasajes del Antiguo Testamento, pone en evidencia una tesis que propone entender el origen de la violencia como un fenómeno proveniente del deseo ${ }^{1}$ o de la imitación ${ }^{2}$. Esa conexión entre violencia y víctima se mimetiza en las prácticas religiosas y sacralizantes en las que el Estado moderno recurre a una figura también moderna del sacrificio como justificación para la preservación de la seguridad y para alcanzar un sentido de "permanencia" o sostenibilidad.

De esta manera, los relatos del Antiguo Testamento a partir de los que se interpreta la necesidad de justificar la violencia estatal, o la que proviene de cualquier tipo de institución, para evitar la ira de Dios $^{3}$, han servido de base para una interpretación ideológica de la Biblia que ha sido usada con el propósito de sostener estructuras de exclusión y segregación, como modernas formas de manifestación de la violencia, cuando los textos bíblicos, en especial el Evangelio, sostienen una tesis completamente diferente. La tesis en la que se sostiene la argumentación del Evangelio, como la "nueva palabra" o palabra de Dios, parte de argumentos que darán una justificación al discurso de la compasión y la solidaridad, apartado o por fuera de toda noción de institucionalidad o religiosidad. Esta visión $-\mathrm{y}$ es la apuesta de este texto - tratará de describir este proceso como una técnica argumentativa que será apropiada por el discurso de los derechos humanos, en el cual toda necesidad de la existencia de una institución, como el Estado o los mercados, o de una ley, para

1 Cfr. Mateo 5, 27: "27 Han oído que se dijo: No cometerás adulterio". La literatura que centra su atención en la discusión del deseo es amplia y comprende desde los estudios de Georg W. F. Hegel hasta las ideas que se discuten de René Girard, sobre todo en lo que resulta pertinente a la tesis de la que parte el presente escrito al ubicar el deseo como la fuente de la mimesis colectiva, en la que subyace la causa fundadora de la violencia. Sobre esto, los seguidores de Girard proponen un amplio estudio en Violence Renounced: René Girard's Biblical Studies and Peacemaking, editado por Willard Swaterly; en lo que se refiere a los derechos humanos, el aporte que hace Costas Douzinas en El fin de los derechos humanos, también ampliamente relacionado en el presente texto, cuando se refiere a Hegel. Cfr. p. 32.

2 Lucas 8, 30-31: “30 Entonces Jesús le preguntó: ¿Cómo te llamas? Y él dijo: Legión; porque muchos demonios habían entrado en él. 31 Y le rogaban que no les ordenara irse al abismo". Girard y algunos de sus comentaristas llamaron a este fenómeno la mala mimesis.

3 Marlin E. Miller, Girardian Perspectives and Christian Atonement, en Violence renounced: René Girard's Biblical Studies and Peacemaking, 31-48, 33 (William M. Swartley, ed., Pandora Press, Telford, Pennsylvania, 2000). 
perpetuarlos, será rechazada. Se entenderá así que los Derechos Humanos no son nociones que el Estado o la ley se puedan apropiar. Esto pone en duda las interpretaciones ideológicas del derecho que, entrado el siglo XXI, se fundan en argumentos de violencia o sacrificio, así como pone en entredicho, de alguna manera, la necesidad del derecho como elemento esencial para la existencia de una sociedad, por lo menos, desde la visión de las tesis de la no violencia de los postulados bíblicos. Esto también sugiere - $\mathrm{y}$ es uno de los pilares en los que se apoya la investigación-, a la luz de los postulados de René Girard y sus críticos, lo que pretende ser la mejor interpretación posible de los textos del evangelio como una reacción poderosa a la violencia que la Biblia rechaza.

Siendo así, el presente ensayo expondrá los argumentos que permiten hablar de la sostenibilidad de los derechos humanos y su origen en la revelación del evangelio contra la violencia. En la primera parte se discutirá sobre el Estado liberal como una de aquellas interpretaciones ideológicas del Antiguo Testamento que desde sus inicios, en la era moderna, ha visto la necesidad de justificar el sacrificio ${ }^{4}$ para evitar su destrucción. El fenómeno de la mimesis desde la perspectiva que ofrece Girard, propone algunas luces sobre la explicación genealógica de la violencia como una necesidad para asegurar las instituciones humanas, sobre todo, la de la ley. La segunda parte discutirá la respuesta de los derechos humanos a la tesis del sacrificio en que se apoya el Estado liberal. Esta respuesta, enmarcada en un menaje secularizante, pone en evidencia la farsa histórica de la sacralidad y religiosidad de un Estado, como la voluntad y piedra angular para perpetuar el mensaje de Dios, lo que da paso a hablar más de la teoría de la compasión y la práctica de la santidad, en vez de la razón mimética de la necesidad de una víctima.

El evangelio, en lo que podría entenderse como una contraofensiva a la perpetuación de la violencia como necesidad ideológica, representa una respuesta a la sacralización de la violencia y de la razón como institución, y que encuentra su manifestación de forma moderna, como respuesta a esa modernidad, inicialmente criticada

4 Marlin E. Miller, Girardian Perspectives and Christian Atonement, en Violence renounced: René Girard's Biblical Studies and Peacemaking, 31-48, 33 (William M. Swartley, ed., Pandora Press, Telford, Pennsylvania, 2000). 
por Georg W. F. Hegel y luego pulverizada por los estudios de Martin Heidegger, en el discurso de los derechos humanos, entendidos estos como el argumento que pone en duda el absolutismo de la razón o la escuela de la racionalidad pero sobre todo de la perpetuación de la violencia y de los discursos ideológicos de poder. A partir de aquí, se espera proponer algunas conclusiones.

\section{LA IRA VENGADORA DE DIOS Y LA RAZÓN DE LA LEY. HERMENÉUTICA SOBRE LA TEORÍA DEL MIEDO}

Ante él tiemblan las montañas; los cerros se derriten en su presencia. Toda la tierra se estremece al verlo; todo el mundo y los que en él viven. (...). Su furia se derrama como fuego, y ante él se parten en dos las peñas.

Nahúm, 1, 5-6

(...) y no hay perdón de pecados si no hay derramamiento de sangre.

Hebreos 9, 22

En el contexto de la religiosidad, los dioses exigen un sacrificio. El pueblo ofrece ese sacrificio como el último acto violento para evitar la ira divina. En ese acto sacrificial, el pueblo se mimetiza en una misma voz, en un mismo acto, en una misma ilusión. En la voz de la violencia que apacigua la ira. En eso se sostenía la tradición antigua para justificar su relación con la divinidad. Hoy, la modernidad exige otro tipo de sacrificio llevado por la razón. Ahora, el pueblo se mimetiza en la voz del partido, de la convención... de la ley. Esto, el sacrificio final, es la "última" expresión de violencia necesaria, pero esta violencia es también moderna, no sangrienta, sino ritual. La víctima no es decapitada, es relegada. La ley, así como los dioses, exige una víctima, aquella víctima que represente la amenaza a los derechos de la voluntad mimetizada. La víctima que debe ser excluida; sacrificada para el bien común como consigna de la modernidad que tiene a la ley como hija más preciada de la razón.

Los Estados de derecho asentados en el discurso de la modernidad de la que se habla desde la Francia de 1789, necesitan justificar y hacer sostenible su existencia mediante su perpetuación. Para esto, la ley y el proceso ritual que se encuentra detrás de ella, se hacen 
poderosos. Esta visión de Estado, que tiene su sustento en lo descrito por Thomas Hobbes, Jean Jacques Rousseau y John Locke, como padres del liberalismo y del pacto social (¿racional?), se convierte en la génesis de la perpetuación de la idea por la necesidad, casi histórica, de un discurso de poder que encuentre una víctima a sacrificar. Por medio de esa justificación se ha tratado de perpetuar una lectura que ha servido de mimesis a la masa o colectividad y cuya principal expresión de las sociedades sacrificiales es la voluntad del soberano ${ }^{5}$, que se autolegitima por el contrato social. Los firmantes de este contrato serán sus primeras víctimas políticas, que es la manera que tiene de actuar el Estado.

El Soberano es un 'Dios Mortal', su único límite es la muerte, 'el amo absoluto'. La ley es el resultado del deseo y de una pulsión de muerte que, mucho antes que lo descubriera Freud, unió a la ley, al deseo y a la muerte. La pasión sin límite crea la soberanía sin límites, la violencia y el temor a ella son la base de la ley.

Aquí se aprecia que la necesidad del hombre por encontrar el sentido de humanidad trata de justificarse, incluso en el texto bíblico, a partir de relaciones sacrificiales, en las cuales la expresión religiosa por la adoración al sacrificio, tal como lo expone Girard7, permite la cabida de la figura del mismo hombre. El concepto de ser humano entra en crisis a partir del posicionamiento de la razón. Las identidades político modernas que se apoyan en las sagradas escrituras, tratan de sostener un discurso de dominación, porque se trata de grupos privilegiados ${ }^{8}$, para evitar la ira divina, de la que habla el Éxodo9. Se trata de estructuras de poder que están amparadas en un evidente discurso racional, netamente justificante de la genealogía de la violencia. Para sobrevivir, estas identidades

5 René GIRARD, El sacrificio (Encuentro, Madrid, 2010).

6 Costas Douzinas, El fin de los derechos humanos, 90 (Óscar Guardiola-Rivera, Ricardo Sanín-Restrepo \& Ómar Alonso-Medina, trads., Legis, Medellín (2008).

7 René Girard, El sacrificio (Encuentro, Madrid, 2010).

8 Diego CAGÜEÑAs-Rozo, Las distancias del creer: secularización, idolatría y el pensamiento del otro, 34 Revista de Estudios Sociales, 123-134, 128 (2009). Disponible en: http://res.uniandes. edu.co/view.php/623/view.php

9 Éxodo 32, 7-10. "7 Entonces el Señor habló a Moisés: Desciende pronto, porque tu pueblo, que sacaste de la tierra de Egipto, se ha corrompido. 8 Bien pronto se han desviado del camino que yo les mandé. Se han hecho un becerro de fundición y lo han adorado, le han ofrecido sacrificios y han dicho: 'Este es tu dios, Israel, que te ha sacado de la tierra de Egipto'. 9 Y el Señor dijo a Moisés: He visto a este pueblo, y he aquí, es pueblo de dura cerviz. 10 Ahora pues, déjame, para que se encienda mi ira contra ellos y los consuma; mas de ti yo haré una gran nación". 
político religiosas ${ }^{10}$ requieren justificarse en la necesidad de ciertas instituciones, como el Estado y la ley para evitar la ira divina. Evitar el estado de caos y alteración del orden, a toda costa. Esta expresión se hará repetitiva a lo largo de la historia en muchas oportunidades cuando la violencia se manifiesta a gran escala contra amenazas, al contrato racional, como Vietnam, Iraq y Afganistán.

Esta posición racional tiene más de ideología que de razón ${ }^{11}$. La figura del Estado liberal y la expansión de su voluntad encuentran mayor justificación en la necesidad de apaciguar la ira de Dios que en otra $\operatorname{cosa}^{12}$, y así mitigar el desencadenamiento de la violencia colectiva. En esto, como lo advierten algunos, se posiciona la visión de un Dios vengativo cuya ira debe ser contenida. La teoría del Estado liberal o Estado razón encuentra gran fundamento en esta visión. Las interpretaciones apocalípticas de los textos bíblicos ${ }^{13}$ llevan al punto de sostener la necesidad de instituciones que permitan asegurar la tranquilidad y supervivencia de la comunidad, y lo que permite su propia cohesión que, como advierte Costas Douzinas $^{14}$, se sostendrá mediante la protección de la propiedad y las leyes del mercado y de las que protegen el mercado, como la ley por excelencia. Aquel que pueda mostrarse como amenaza a las instituciones del hombre y el ejercicio de sus derechos civiles es una amenaza a las instituciones de Dios, por lo cual se justifica su sacrificio para evitar la ira contra el pueblo de Israel. Aquí inicia el proceso de trabajo conjunto entre la iglesia y el Estado, que lleva a su confusión, sobre todo bajo el afán de la política monárquica de Hobbes, de justificar al monarca como Dios sobre la tierra. Siguiendo a Douzinas ${ }^{15}$, en ese punto, Thomas Hobbes, el primer

10 Willard M. Swartley, Discipleship and Imitation of Jesus/Suffering Servant: The Mimesis of New Creation, en Violence renounced: René Girard's Biblical Studies and Peacemaking, 218-245 (William M. Swartley, ed., Pandora Press, Telford, Pennsylvania, 2000).

11 René Girard, La violencia y lo sagrado, 10 (Anagrama, Barcelona, 1995).

12 Marlin E. Miller, Girardian Perspectives and Christian Atonement, en Violence renounced: René Girard's Biblical Studies and Peacemaking, 31-48, 37 (William M. Swartley, ed., Pandora Press, Telford, Pennsylvania, 2000).

13 Entre estos textos, están Mateo 24, 1-46; Marcos 13, 1-37. Cfr. Marlin E. Miller, Girardian Perspectives and Christian Atonement, en Violence renounced: René Girard's Biblical Studies and Peacemaking, 31-48, 41 (William M. Swartley, ed., Pandora Press, Telford, Pennsylvania, 2000).

14 Costas Douzinas, El fin de los derechos humanos (Óscar Guardiola-Rivera, Ricardo Sanín-Restrepo \& Ómar Alonso-Medina, trads., Legis, Medellín, 2008). Con particular atención, pueden consultarse los capítulos 3 y 4.

15 Costas Douzinas, El fin de los derechos humanos, 90 (Óscar Guardiola-Rivera, Ricardo Sanín-Restrepo \& Ómar Alonso-Medina, trads., Legis, Medellín, 2008). 
rousseauniano antes de Rousseau, reinterpreta el derecho natural para justificar la actuación del monarca como dios mortal, legitimado para hacer violencia porque "el hombre se volvió Dios" ${ }^{\text {. }}$. Esto es derecho pero no derechos.

La teología secular de los derechos naturales puso el concepto abstracto de hombre en el centro del universo y le transfirió a él la adoración ofrecida por los medievales a Dios. Los aspectos prudentes y visionarios de la teoría del 'mejor gobierno' fueron minados pero, al mismo tiempo, la receptividad de un derecho natural clásico se volvió un horizonte potencial para el derecho y la identidad individuales ${ }^{17}$.

La individualidad potencia la idea de definir, no al sujeto y su relación con la colectividad, lo que parece desaparecer de las prioridades filosóficas que fundaron los clásicos, para dar paso a la necesidad de autopreservación de la colectividad en la que el individuo se ha mimetizado, al renunciar a su autonomía. Si el egoísmo es el fundamento del pecado original que trata de revelar Cristo con diversos ejemplos, en el individuo moderno, por su parte, confluye la fuerza originaria del mal que da vida al pecado.

Todo aquello que atenta contra el individuo justifica la reacción del protector de la razón. La violencia contra la propiedad, como esencia que permite la materialización del sujeto y su relación con el entorno, es entendida como la prevención de la ira de Dios contra quienes le son infieles.

Al respecto, Marlin Miller advierte:

In the Old Testament, wrath is frequently associated with Yahweh, the covenant God, but it is rarely unmotivated or arbitrary. (...) God wrath has to do with God's jealously to preserve the covenant relationship and is therefore directed primarily against an unfaithful Israel. God's wrath is also sometimes seen in unpredictable and catastrophic events that affect all people, but even these are increasingly seen as the result of Israel's covenant violation. Hence the 'response of God's wrath' is called forth by unfaithfulness to the covenant ${ }^{18}$.

16 Costas Douzinas, El fin de los derechos humanos, 76 (Óscar Guardiola-Rivera, Ricardo Sanín-Restrepo \& Ómar Alonso-Medina, trads., Legis, Medellín, 2008).

17 Costas Douzinas, El fin de los derechos humanos, 76 (Óscar Guardiola-Rivera, Ricardo Sanín-Restrepo \& Ómar Alonso-Medina, trads., Legis, Medellín, 2008).

18 Marlin E. Miller, Girardian Perspectives and Christian Atonement, en Violence renounced: René Girard's Biblical Studies and Peacemaking, 31-48, 41 (William M. Swartley, ed., Pandora Press, Telford, Pennsylvania, 2000). 
Esa víctima que se muestra como necesaria, en los términos de la Ilustración, como extremismo racional en el que se ampara el germen del Estado liberal, es vista como todo aquel que se oponga a la conservación y preservación del hombre. Esto es, toda institución o ritual, dice Girard, que mantenga la unidad de la comunidad. Entre estas, su derecho de propiedad aparece como la más relevante y es lo que la ley aspira proteger. Esto significa proteger a toda costa la máxima expresión del liberalismo y la máxima institución de la modernidad, pues es la que permite la subsistencia ${ }^{19}$ de las cosas del hombre. Así, toda amenaza a su supervivencia justifica la reacción violenta, sobre todo porque amenazar la convivencia del pueblo de Dios es amenazar a Dios.

Para legitimar esta violencia, la ley no solo la legitima sino que la sacraliza. El ritual ya no es el sangriento evento de mutilación o muerte. Ahora, se trata de una concertación de intereses hegemónicos y círculos de poder, reunidos en una misma causa: conservar una estructura ideológica, sea ya económica, social o política. Aquí los mercados, la seguridad y la noción de orden ganan preponderancia como instituciones perfectas, sobre todo los primeros, porque permiten el reparto, también perfecto, de los derechos de los propietarios capaces y con vocación mercantil. Tal será el impacto de los mercados que solo 200 años después se empezará a hablar de sus fallas y limitaciones.

La ley civil se crea a través del avance imparable de los derechos individuales, el fin de la ley es la creación de los derechos. Pero estos son derechos privados únicamente. Los derechos públicos, derechos en contra del Estado, están excluidos totalmente. (...). Los derechos públicos y privados, aunque formalmente similares, son claramente diferentes. La condición previa de los derechos de propiedad individuales es la ausencia de derechos políticos y humanos, la sujeción es la condición previa de la libertad ${ }^{20}$.

Primero, el esclavo era la garantía de la propiedad; el sometimiento del indio permite la explotación de la tierra; la exclusión de la mujer permite el progreso; ancianos, discapacitados, e incluso religiones diferentes, son inexistentes. Se trata de sujetos que no

19 Costas Douzinas, El fin de los derechos humanos, 99 (Óscar Guardiola-Rivera, Ricardo Sanín-Restrepo \& Ómar Alonso-Medina, trads., Legis, Medellín, 2008).

20 Costas Douzinas, El fin de los derechos humanos, 97 (Óscar Guardiola-Rivera, Ricardo Sanín-Restrepo \& Ómar Alonso-Medina, trads., Legis, Medellín, 2008). 
representan nada porque no guardan ningún valor económico. Víctimas necesarias para la perpetuación del Estado, lo que el liberalismo francés denomina el ritual del pacto social. El título de propietario es la garantía de acceso a derechos del mercado: los derechos que diga y otorgue la ley civil ${ }^{21}$. Tipos de víctimas de diferentes tipos de leyes en diferentes lugares y tiempos.

El método clásico de la sujeción se basó en una jerarquía estrictamente ontológica, que clasificó la dignidad y el honor y que habilitaba a algunos para participar en la vida politica, mientras que otros, como niños, mujeres, extranjeros o esclavos, estaban siempre subyugados a aquellos superiores a ellos en la jerarquía social22.

Más adelante, Douzinas define este tipo de victimarios como sujetos institucionales modernos. Este texto resume esa idea, según la cual el mercado es la institución por excelencia, que se muestra como la fuente de la desigualdad a la que pretendía oponerse.

Las economías capitalistas necesitan sujetos fragmentados, que traten su poder laborioso como materia prima para ser libremente intercambiada en el mercado laboral por la consideración de salarios. Marx expuso brillantemente la dinámica fundamental de estas formas e insistió en la discrepancia entre la libre elección y la autodeterminación individual que mantiene el discurso de los derechos y la explotación, el sufrimiento y la injusticia causados por el sistema económico el cual creó estos conceptos e instituciones. De nuevo, el psicoanálisis, una teoría y práctica obsesionada con el sujeto, atribuye su génesis a la introducción del niño al orden simbólico, en otras palabras a su sujeción al lenguaje y a la ley ${ }^{23}$.

Esto representa el deseo del sujeto por unirse a una colectividad que proteja sus intereses comunes, y que le permita mimetizarse en ellos. La colectividad, en la que cada quien tiende a actuar como los otros, sin que esto represente la imitación ${ }^{24}$. La actuación co-

21 Costas Douzinas, El fin de los derechos humanos, 94 (Óscar Guardiola-Rivera, Ricardo Sanín-Restrepo \& Ómar Alonso-Medina, trads., Legis, Medellín, 2008).

22 Costas Douzinas, El fin de los derechos humanos, 263 (Óscar Guardiola-Rivera, Ricardo Sanín-Restrepo \& Ómar Alonso-Medina, trads., Legis, Medellín, 2008).

23 Costas Douzinas, El fin de los derechos humanos, 271 (Óscar Guardiola-Rivera, Ricardo Sanín-Restrepo \& Ómar Alonso-Medina, trads., Legis, Medellín, 2008).

24 Robin Collins, Girard and Atonement: An Incarnational Theory of Mimetic Participation, en Violence renounced: René Girard's Biblical Studies and Peacemaking, 132-150, 134 (WILliam M. Swartley, ed., Pandora Press, Telford, Pennsylvania, 2000). Disponible en: http://home. messiah.edu/ rcollins/Philosophical\%20Theology/Atonement/Swart7.rtf 
lectiva es la que va a justificar la búsqueda de una víctima que es identificable, como en los casos arriba enunciados, a diferencia del victimario que no puede individualizarse, lo que hace más atractivo hacer parte de la mimesis.

Amparada en un discurso justificado más en el miedo que en la razón, sobre todo en el miedo a morir y perder aquello que se posee, la mimesis ubica a su víctima necesaria como el objetivo de la voluntad colectiva que se adhiere a la voluntad de la ley, para apaciguar el miedo colectivo mimetizado, y encontrar su chivo expiatorio, ya no para agradar al dios, sino para preservar las instituciones sociales y políticas. Es lo que se entiende como "la cultura religiosa" 25 . La necesidad del sacrificio se justifica porque esa víctima amenaza la institucionalidad, el orden, la paz. La ley se convierte en el instrumento de sacralización de la violencia como justificación de la violencia del hombre por el hombre. La ley sacralizada se opone al mensaje de santificación y reconciliación, que sería a lo que en su momento reaccionó el Evangelio.

Esa víctima - niños, mujeres, ancianos y todo aquel que la ley considere incapaz o amenazante al orden - se muestra como necesaria en los términos de la Ilustración, como extremismo racional en el que se ampara el germen del Estado liberal. El sacrificio de la víctima se justifica porque esta es vista como todo aquello que se oponga a la conservación y preservación del hombre. Esto es, toda institución o ritual, dice Girard, que mantenga la unidad de la comunidad, para lo cual no hay nada más adecuado que delimitar el concepto de propiedad, como el concepto sinónimo de la modernidad, y punto de protección al que aspira la ley. Para proteger la máxima expresión del liberalismo y la máxima institución de la modernidad, pues este es el que permite su subsistencia. Así, toda amenaza a su supervivencia justifica la reacción violenta, sobre todo porque amenazar la convivencia del pueblo de Dios, es amenazar a Dios, lo que justifica una respuesta contra aquella amenaza.

La búsqueda de la felicidad y de la autoconservación requiere la propiedad, y el principal propósito de la sociedad civil debería ser la protección de la propiedad.

25 René Girard, El sacrificio, 52 (Encuentro, Madrid, 2010). 
Como resultado, el cuerpo legislativo debería ser elegido por las clases pudientes para asegurar que los derechos de propiedad no se pusieran en peligro ${ }^{26}$.

Desde la tesis de la santidad o, simplemente, de la reacción contra toda forma de violencia, la lectura que se hace desde el evangelio sobre lo que compone el mensaje de Cristo y el revelador significado de su muerte en la cruz, se consolida como el contraargumento que pone en evidencia la violencia mimetizada. El evangelio propone renunciar a ella mediante la identificación de la teoría del deseo de la que habla Hegel como manifestación de la relación de poderío ${ }^{27}$ y en la puesta en evidencia del mal. Este es el punto de partida para el posicionamiento de los derechos humanos como manifestación de esta crítica.

\section{CRÍticas A LA DOCTRINA DE LA VIOLENCIA MODERNA: DEL ESTOICISMO A LA TESIS DE LOS DERECHOS HUMANOS}

Ustedes han oído que antes se dijo: No cometas adulterio. Pero yo les digo que cualquiera que mira con deseo a una mujer, ya cometió adulterio con ella en su corazón.

Evangelio según San Mateo 5, 27-28

El naturalismo estoico hace una primera advertencia sobre cómo el fenómeno de expansión y perpetuación de la violencia se sostiene en la ley romana. Se trata de una respuesta formal pero con un contenido igualmente crítico a la fundamentación de la violencia, tal como lo hace el texto evangélico. En concreto, el derecho estoico pone en evidencia esa crítica al imperio del poder, como una estructura sacralizante y religiosa que se opone a la misma noción del ser humano, como sujeto libre. La filosofía estoica, muy cercana a los textos del evangelio, en la antesala de la tesis de los derechos humanos, advierte sobre el fenómeno del deseo como expresión de la violencia.

26 Costas Douzinas, El fin de los derechos humanos, 99 (Óscar Guardiola-Rivera, Ricardo Sanín-Restrepo \& Ómar Alonso-Medina, trads., Legis, Medellín, 2008).

27 Georg W. F. Hegel, Fenomenología del Espíritu, 269 (Abada, Madrid, 2010). Costas Douzinas, El fin de los derechos humanos, 323 (Óscar Guardiola-Rivera, Ricardo Sanín-Restrepo \& Ómar Alonso-Medina, trads., Legis, Medellín, 2008). 
Ahora, hay una respuesta que viene desde la conceptualización del hombre y su retorno a su condición natural. Toda expresión en la que el hombre se encuentra con el otro, define la humanidad a partir no de una igualdad forzada e irreal, sino de su libertad. En el sentido que lo señala $\mathrm{Hegel}^{28}$, la autonomía es imposible sin el otro. Definir al hombre con su necesidad de deseo de lo que desea el otro, pero aceptando el mensaje secularizante de aislar el sacrificio. Como lo advierte su noción de secularización, de alguna manera cercana a la del estoicismo que señala Douzinas ${ }^{29}$, existe una preocupación por la violencia entre unos y otros. Cuando se sacrifica una víctima en nombre del poder o de los mercados, el hombre pierde la capacidad para autodefinirse, porque el hombre mata al otro en el que se reconoce a sí mismo, casi por necesidad. La respuesta y crítica, ya se advertía.

Los derechos humanos, como mensaje de reconciliación y entrega legado por el cristianismo, hablan de santidad y son una reacción contra la ley romana que asesinó a Cristo en la cruz y negó la humanización ${ }^{30}$. La ley y toda la racionalidad inquebrantable que representa, desvió la atención en el ser humano y ritualizó los derechos del hombre para convertirse en el punto de explosión de la máxima expresión de la violencia moderna. La exclusión del otro y la explotación del otro por el yo. El cristianismo, la crítica estoica y la filosofía antropológica que se pregunta por el $\operatorname{ser}^{31}$, advierten sobre esto. Se trataba de los derechos humanos, no los derechos de la ley. Se trata del sacrificio por el otro no del otro.

Mi identidad es el resultado del reconocimiento de mis características por parte del otro. Este reconocimiento de la contribución vital del otro para la constitución del ser expone al ser a la acción del valor universal y lo reconcilia con el mundo. Al mismo tiempo, la identidad que se creó a través del reconocimiento del otro me hace consciente de mi especificidad y de mi diferencia de los demás ${ }^{32}$.

28 Georg W. F. Hegel, Fenomenología del Espíritu, 269 (Abada, Madrid, 2010).

29 Costas Douzinas, El fin de los derechos humanos (Óscar Guardiola-Rivera, Ricardo SanínRestrepo \& Ómar Alonso-Medina, trads., Legis, Medellín, 2008).

30 Costas Douzinas, El fin de los derechos humanos (Óscar Guardiola-Rivera, Ricardo SanínRestrepo \& Ómar Alonso-Medina, trads., Legis, Medellín, 2008).

31 Básicamente, se trata de lo que podría denominarse la filosofía posmoderna que reacciona a las tesis del Estado liberal y el pacto social. Aquí ubicaríamos a Heidegger como un referente, sin que pueda delimitarse esa filosofía antropológica a una sola escuela, tiempo o sujeto; sí se trata de una posición crítica sobre la modernidad pero sobre todo a la violencia que este término representa.

32 Costas Douzinas, El fin de los derechos humanos, 329 (Óscar Guardiola-Rivera, Ricardo Sanín-Restrepo \& Ómar Alonso-Medina, trads., Legis, Medellín, 2008). 
Por otra parte, el discurso de los derechos humanos, sostenido en la tradición estoica que se hizo de la ley a la luz de los ejemplos de Cristo, se basa en los principios naturales del cristianismo, para tratar de dotar al individuo de una identidad ${ }^{33}$. Sobre esto parece asentarse el trabajo de Hegel al momento de entender la muerte de Cristo como la fuente de la desacralización del Estado. Esto implica definirse no a partir del deseo, sobre todo el deseo egocéntrico de superponerse al otro, que es el punto originario de la violencia. Esto es Hegel desde una visión reconciliadora de lo que parece ser la expresión más violenta del hombre: la necesidad de desear, de ser otro.

Aquí puede decirse que el concepto de derechos empieza y acaba por lo que Hegel entiende como el respeto a sí mismo. La identificación de uno mismo en el reconocimiento del otro. Aquí la ley sobra completamente. Hegel nos da su percepción del hombre y su papel antropológico. Es más útil hablar de reconciliación y reconocimiento que de la ley, para definir la dignidad humana y lo que se entiende por mutuo respeto, en que el hombre se convierte en el fin de la humanidad. La tesis de los dogmas teológicos ${ }^{34}$ sobre la ira de Dios y el miedo, es falsa, o más precisamente, insostenible a la luz del acto de reconocer y reconciliarse con el otro.

Esto implica reconocerlo en su dignidad y reconocer en el otro las propias necesidades, falencias y temores, para superar el deseo egoísta que Cristo clarifica en pasajes del evangelio sobre todo en aquellos que rechazan la necesidad del individuo de adherirse a algo o a alguien. En esta mimesis, está el origen del mal. Por el contrario, a modo del mensaje evangélico, la vida del individuo como sujeto colectivo que se hace en la santidad por el otro, no es otra cosa que el morir por el otro. Sacrificarse por el otro, no al otro.

Recordando a Girard, cuando se habla del rito que lleva al proceso mimético de la violencia de los dioses modernos, se habla de la fuente de la subyugación y la exclusión del otro que empieza por la negación y, en algunos casos, la aniquilación total de sus derechos como "chivos expiatorios" o sacrificios justificados para

33 Costas Douzinas, El fin de los derechos humanos, 329 (Óscar Guardiola-Rivera, Ricardo Sanín-Restrepo \& Ómar Alonso-Medina, trads., Legis, Medellín, 2008).

34 Hans Blumenberg, Descripción del ser humano, 367 (Fondo de Cultura Económica, México, 2011). 
conservar el orden y la seguridad, sobre todo la de las leyes de los mercados que garantizan la propiedad. El Estado razón, que habla por medio de las instituciones clásicas del derecho, muchas de ellas trasplantadas desde las antiguas tradiciones romanas y neoplatónicas ${ }^{35}$, se ha convertido en la fuente de eliminación de la libertad y autonomía del hombre, hasta llegar a la negación de su concepto como sujeto.

La función de los Estados y de las leyes es coartar a los hombres, restringir su cupiditas o deseo infinito y mantener la paz en esas ciudades del demonio. Por consiguiente, el Estado no tiene legitimidad intrínseca e inclusive las naciones más exitosas están destinadas a declinar y desaparecer. Solo sirven para confrontar la violencia interna y externa con violencia ${ }^{36}$.

En este sentido, el argumento de los Derechos Humanos aparece como la desacralización de las instituciones que el Estado de derecho ha legitimado. La razón, que se hizo ley escrita, es una visión moderna (hija de la Ilustración) de la violencia y, sobre todo, de la legitimización de la fuerza del vencedor, mediante un discurso que habla de hacer justicia con la víctima sacrificada. Más precisamente, será vengar el sacrificio por orden de la ley, lo que Costas Douzinas precisa muy bien al relacionar la génesis de la violencia en las instituciones legales, como los contratos, como protectores de los mercados a partir de la exclusión.

La ley civil se crea a través del avance imparable de los derechos individuales, el fin de la ley es la creación de los derechos. Pero estos son derechos privados únicamente. Los derechos públicos, derechos en contra del Estado, están excluidos totalmente. La creación y disfrute de los derechos privados está acompañada por una ausencia de lo que ahora llamamos derechos humanos. El precio que se debe pagar por la protección contra otros es la mínima protección contra el Estado. Los derechos privados son el fin y el valor del sistema de ley, que se vuelve un sistema de derechos subjetivos, de sus precondiciones y consecuencias: los contratos, un Estado fuerte y una ley absoluta ${ }^{37}$.

35 Costas Douzinas, El fin de los derechos humanos, 73 (Óscar Guardiola-Rivera, Ricardo Sanín-Restrepo \& Ómar Alonso-Medina, trads., Legis, Medellín, 2008).

36 Costas Douzinas, El fin de los derechos humanos, 65 (Óscar Guardiola-Rivera, Ricardo Sanín-Restrepo \& Ómar Alonso-Medina, trads., Legis, Medellín, 2008).

37 Costas Douzinas, El fin de los derechos humanos, 97 (Óscar Guardiola-Rivera, Ricardo Sanín-Restrepo \& Ómar Alonso-Medina, trads., Legis, Medellín, 2008). 
El argumento de la universalidad normativa ${ }^{38}$ en el que se amparó la revolución, es la negación de la individualidad. En la mimesis perfecta todos caben, sobre todo, los que están dispuestos a adoptar a la violencia y justificar el sacrificio para crear un ambiente de seguridad. Asegurar a dos como iguales equivale a formalizar el concepto de individuo, homogeneizarlo y olvidarse de la indagación sobre la verdad de la que habla Heidegger ${ }^{39}$. Esta es la pérdida necesaria que implica encontrar la tranquilidad contra todo aquello que amenaza lo propio, lo que es de cada quien, y sobre lo que se puede ejercer el derecho privado. Es la ley la que habla para justificar el principal derecho: la propiedad. El respeto por el otro implica la seguridad de todos y justifica la violencia como "legítima defensa". El concepto de hombre en la Ilustración es claro. Se renuncia al individuo para garantizar la seguridad y unidad de todos. Es el sacrificio que se debe asumir, la negación de la identidad del sujeto si se quiere ser beneficiario de la ley y sus derechos privados. Este es el legado más ilustrado, si se quiere ver así, de la modernidad: "So, another way of thinking about Girard's mimetic theory of desire (...) is that we typically participate in the desires of the community, instead of merely generating or having them individualistically" 40 .

El temor del que se hablaba arriba, como fuente de violencia y mimetización en la colectividad, pero también como muestra de inseguridad, es el origen de la negación y del olvido por el ser como individuo.

38 Costas Douzinas, El fin de los derechos humanos, 79 (Óscar Guardiola-Rivera, Ricardo Sanín-Restrepo \& Ómar Alonso-Medina, trads., Legis, Medellín, 2008).

39 Martin Heidegger, Carta sobre el humanismo (Taurus, Madrid, 1996).

40 Robin Collins, Girard and Atonement: An Incarnational Theory of Mimetic Participation, en Violence renounced: René Girard's Biblical Studies and Peacemaking, 132-150, 134 (WILliam M. Swartley, ed., Pandora Press, Telford, Pennsylvania, 2000). Disponible en: http://home. messiah.edu/ rcollins/Philosophical\%20Theology/Atonement/Swart7.rtf 


\title{
III. FUNDAMENTACIÓN DE LOS DERECHOS HUMANOS COMO MANIFESTACIÓN DE LA SECULARIZACIÓN... O SOBRE LA DESACRALIZACIÓN DE LA LEY
}

\begin{abstract}
Muchas veces el demonio se había apoderado de él; y aunque la gente le sujetaba las manos y los pies con cadenas para tenerlo seguro, él las rompía y el demonio lo hacía huir a lugares desiertos. Jesús le preguntó: ¿Cómo te llamas? $Y$ él contestó: Me llamo legión.

Evangelio de San Lucas 8, 29-30
\end{abstract}

El hombre es la revelación del misterio de Dios. Al conocer a Dios y entender el fenómeno que describe el paso de la muerte a la vida, encuentra la razón de ser del actuar en Dios y lo que representa la santidad como rompimiento de la sacralidad. El hombre al entender a Dios en el proceso muerte-resurrección, se hace libre. Este entendimiento lo libera de toda atadura religiosa, pero sobre todo de las cadenas de la soberbia de la ley.

En este contexto, los derechos humanos se muestran como el paso a la resurrección. El ser se encuentra consigo mismo para descubrir su identidad. Aquello que legitimaba la violencia, como el grito sediento de la mayoría mimetizada en un discurso de igualdad que se oye desde 1789 en Francia, se pone en evidencia. El hombre no necesita de la adoración de esa mayoría para definirse, y mucho menos para ser libre. Se trata de reconciliarse con el otro. Morir, como el fin de la vida de violencia, para dar paso a la vida en convivencia. Los derechos humanos ponen en evidencia esa necesidad de adoptar la ley como un dios falso, en el que se pasa del miedo a la violencia para mantener el poder. La ley violenta y vengadora que se convirtió en la causa de la negación de la naturalidad del hombre, esto es la relación consigo mismo, es revelada por los derechos humanos como la fuente de la subyugación. El hombre se libera de las ataduras de la razón colectiva, como cuando Jesús libera de las ataduras de los demonios. El hombre da el paso a la nueva vida para lo cual no necesita religión ni victimización.

El hombre asume el papel de indagarse por su relación consigo mismo y con el otro, en la tensión constante por vencer las ansias de deseo de las que habla Hegel; en esto consiste la posibilidad que 
ofrecen los derechos humanos. En esto, los derechos humanos y el evangelio regresan a su misma fuente de origen: la caridad y la práctica de la reconciliación.

El argumento de la solidaridad pasa a ser la filosofía a seguir ${ }^{41}$. En esto, Costas Douzinas coincide con Martin Heidegger, cuando ponen de presente que el fundamento de los derechos humanos se hace simple cuando se hace la diferencia entre ser y sujeto. El ser es el que reconoce al otro como libre porque él mismo es libre, siguiendo a Georg W. F. Hegel, en el afán de superar la teoría del miedo que justifica el sacrificio. El sujeto es el que se encuentra sujetado por el temor. Las cadenas de la ley lo subyugan; pero le dan seguridad, tranquilidad ${ }^{42}$. La superación del miedo viene por una opción evangélica. Seguir en la búsqueda por la práctica de la caridad como mandamiento sin ley, es más, en contra de toda ley. El costo representa oponerse al institucionalismo en todas y cada una de sus versiones que la modernidad racional hace manifiestas. En esta medida, el ser es aquel que puede practicar la santidad sobre la tierra y en la que recupera su identidad, recuerda quién fue. Esa noción de cristiandad se diferencia de la que predica la relación Iglesia-Estado, en lo que simplemente es la repartición negociada de las fuentes del poder o, más bien, del derecho, y que va a quedar formalizada en un pacto entre iguales que excluye al diferente, tal como se argumentó arriba.

El reto que propone el evangelio es el de practicar el amor con el enemigo. Esto implica renunciar al temor que da origen al deseo. Lo difícil de la tesis evangélica es lo que implica renunciar a la seguridad que ofrece la ley para ser capaces de actuar en la práctica de la fe, la esperanza y la caridad, como mecanismos de cambio. Aquí está la clave que descifra el mensaje de morir para vivir. El cambio de condición pero sobre todo renunciar a la religiosidad, como un mensaje ateo, es la nueva vida que representa la secularización del texto bíblico. Renunciar al pecado mayor: el deseo.

Love, as understood in the sense of desiring the subjectivity of one self and others (...). According to this idea, to desire the subjectivity of another is to

41 Costas Douzinas, El fin de los derechos humanos, 335 (Óscar Guardiola-Rivera, Ricardo Sanín-Restrepo \& Ómar Alonso-Medina, trads., Legis, Medellín, 2008).

42 Costas Douzinas, El fin de los derechos humanos, 248 (Óscar Guardiola-Rivera, Ricardo Sanín-Restrepo \& Ómar Alonso-Medina, trads., Legis, Medellín, 2008). 
desire them to be separate centers of consciousness and will, who not only are presently in relationship with oneself but who are rich with future possibilities of growth and interrelationship ${ }^{43}$.

Esta renuncia, sobre todo lo que implica apartarse de la fuente del mal, implica abrir el paso a la formación de una comunidad de hombres libres, en la cual el ser practica la reconciliación en el otro y reconstituye la noción de individuo. El deseo del otro es mi deseo de materializar una relación entre quienes están en la misma condición. Sujetos titulares de necesidades que los hacen iguales y les dan un sentido de ver al otro como el hermano que Cristo veía en sus apóstoles para garantizar la práctica del apostolado en el que prima la enseñanza de la fraternidad. Este es un principio positivo en el que se funda la argumentación pero sobre todo materialización de los derechos humanos. En ningún momento aparece la necesidad de un Estado que oriente esta práctica.

Solo la renuncia a la prevalencia del yo como centro de referencia, es lo que permite hablar más de una noción de convivencia que de espacio para hablar sobre paz; a esto es a lo que las leyes de los mercados y de los derechos civiles, como herederos de la modernidad, todavía se oponen, y, sobre todo, recuperar una noción de ser definida por el sujeto propio, sin interferencia ni ayuda de la ley.

\section{EL ASCENSO DE LOS ÍDOLOS}

En lo que parece un triunfo final de los derechos humanos, al advertir y poner en evidencia la centralidad del ser, no del sujeto sujetado, aparece el siguiente inconveniente. Heidegger había calificado la crisis sobre la noción del ser y de su olvido como lo que representa la crisis de la humanidad. El exterminio judío, Kosovo, Yugoslavia, a escala global, y la Regeneración (1886-1910), Chile y Argentina en las décadas de 1970 y 1980, el Frente Nacional, la Seguridad Democrática, como fenómenos locales en América Latina, y cualquier otra manifestación humana de autoritarismo globalizado revelan la crisis por el posicionamiento del ser. Esas muestras de discursos

43 Robin Collins, Girard and Atonement: An Incarnational Theory of Mimetic Participation, en Violence renounced: René Girard's Biblical Studies and Peacemaking, 132-150, 143 (WILliam M. Swartley, ed., Pandora Press, Telford, Pennsylvania, 2000). Disponible en: http://home. messiah.edu/ rcollins/Philosophical\%20Theology/Atonement/Swart7.rtf 
ideológicos que coinciden en que se apoyan y adoran la ley como un ídolo, silenciaron la identidad del ser humano, lo que las convierte en el acto más violento de la modernidad, porque impiden a cada quien o a cada víctima sentar su posición y sentido de diferencia. Esto demuestra lo difícil que hoy se hace hablar de un mundo secularizado. El hombre, bajo los regímenes del temor (¿terror?), busca un nuevo dios qué adorar, sean los mercados modernos o la guerra por el capital, llámese petróleo, seguridad o minería; esto implica que una nueva religión nace y encuentra seguidores rápidamente, para poder justificar sus actos de sometimiento y miedo.

La expansión de estos discursos demuestra lo que Cagüeñas ${ }^{44}$ denomina la pervivencia de conceptos o tradiciones que se han ido mimetizando para subsistir en nociones que renuevan el discurso de la modernidad y lo conectan con lo religioso, lo que revela la crisis del ser y el triunfo del desplazamiento de la santidad y de pensar al otro, por la idea de sacrificio como una necesidad histórica. Esto es lo que Douzinas, parafraseando a Heidegger, advierte: "El olvido del hombre se agravó en la modernidad"45.

Los derechos humanos ponen en evidencia la crisis de la ley y su soberbia racional, tal como lo hizo manifiesto Cristo en la sociedad de su momento, sobre todo de la ley que justificaba la violencia. La tesis sobre la ira de Dios y la necesidad de un dios vengativo es falsa y con esto mueren las tesis ideológicas del miedo para sostener la igualdad de todos como manera de defenderse del diferente. Se trata, por el contrario, de acuerdo a los textos del evangelio y lo que representa el significado de la muerte de Cristo en la cruz para la concepción de los derechos humanos, de un Dios de misericordia, pero sobre todo de un Dios que desnuda la genealogía de la violencia que encuentra su semilla en la negación de la individualidad del otro, mediante un ejemplo de reconciliación, algo que políticamente no encuentra mucho atractivo, además de resultar peligroso para la sostenibilidad de la seguridad y conservación, sobre todo para el discurso institucional en que se asienta la amoralidad de la modernidad. La muerte de Cristo, para los objetivos de este texto,

44 Diego Cagüeñas-Rozo, Las distancias del creer: secularización, idolatría y el pensamiento del otro, 34 Revista de Estudios Sociales, 123-134, 124 (2009). Disponible en: http://res.uniandes. edu.co/view.php/623/view.php

45 Costas Douzinas, El fin de los derechos humanos, 248 (Óscar Guardiola-Rivera, Ricardo Sanín-Restrepo \& Ómar Alonso-Medina, trads., Legis, Medellín, 2008). 
representa el desafío a las fuentes de violencia de la manera más clara posible: poniéndola en evidencia. Esto, al negar la necesidad de la víctima para apaciguar la ira de Dios y, por el contrario, posicionar a la víctima en un papel que recuerda el discurso de los derechos y la renuncia a la violencia, como lo deja ver el siguiente fragmento.

Girard suggests that 'Jesus had to die because continuing to live would mean a compromise with violence... Here we have the difference between the religions that remain subordinated to the powers and the act of destroying those powers through a form of transcendence that never acts by means of violence, is never responsible for any violence, and remains radically opposed to violence ${ }^{46}$.

En este punto subyace la tesis de la secularización y renuncia a los dioses y rituales religiosos, sobre todo cuando no hay nada más religioso que el formalismo excluyente en que se escuda el legislador para hacer la ley. Como lo advierte Girard, la violencia tiene muchas razones para existir y justificarse a sí misma ${ }^{47}$.

Sin embargo, la modernidad resurgió en el grito agónico de la Revolución y ubicó al hombre otra vez como el centro del universo y de la filosofía, a partir de una razón que busca justificaciones o, más precisamente, víctimas para perpetuarse. Ya no se trata del origen de la maldad, sino del retorno a ella. Los derechos humanos llaman la atención sobre la evidente mimesis entre los ciudadanos del Estado liberal, con lo que se niega el individuo libre. Eso lo advierte el estoicismo con su postura naturalista, Hegel desde la muerte de Cristo en la cruz y la renuncia al deseo del otro. Estos, y otros que retornan a las tesis evangélicas, coinciden en que el sujeto no requiere alienarse o mimetizarse para subsistir que es a lo que lo obliga el Estado cuando se vuelve un sujeto con intereses en el mercado y desvía su atención de crear espacios de inclusión fuera de la ley. El empeño de los derechos humanos en negar toda colectividad como necesidad histórica y violencia masificada, fracasa.

Los fenómenos de violencia colectiva, que ahora se denomina violencia política, y sobre todo cada vez más masificada, tanto desde

\footnotetext{
46 Marlin E. Miller, Girardian Perspectives and Christian Atonement, en Violence renounced: René Girard's Biblical Studies and Peacemaking, 31-48, 37 (William M. Swartley, ed., Pandora Press, Telford, Pennsylvania, 2000).

47 René Girard, El sacrificio (Encuentro, Madrid, 2010).
} 
el punto de vista del victimario como de la víctima, que ahora se manifiesta en masacres, desaparición de grupos políticos y holocaustos, son el triunfo de la teoría del miedo por la individualidad. Ante esto, los derechos humanos parecen intentar hacer una última advertencia, cuando se mira en una perspectiva crítica del ser humano y su papel en la sociedad ${ }^{48}$.

La crisis de los derechos humanos se agudiza en su propio nacimiento cuando la ley intentó hacerlos suyos, pues son de los hombres. La teoría del sacrificio como explicación genealógica de la violencia, y la postura de Hegel, entre otras, sobre la teoría del conflicto, parecen advertir el decaimiento del discurso secularizado sobre el rechazo al racionalismo moderno y absolutizante. Esto representa la derrota de la palabra salvadora del Nuevo Testamento. Es la victoria de la metafísica del olvido del ser sobre la cuestión antropológica del ser. Resta por preguntarse, si el Estado Social tiene algo para decir.

48 Costas Douzinas, El fin de los derechos humanos, 271-273 (Óscar Guardiola-Rivera, Ricardo Sanín-Restrepo \& Ómar Alonso-Medina, trads., Legis, Medellín, 2008). 


\section{CONCLUSIONES}

¿Qué propone una lectura bíblica de los derechos humanos a las preguntas del derecho? Al hablar del deseo particular y de la mimesis como el fenómeno de la entidad colectiva, y ubicarlos como las "fuentes formales" de la violencia moderna, a partir de una de las lecturas más relevantes (pero no la única) que se hace de los textos bíblicos, la antropología filosófica y, con esto, la filosofía del derecho hacen una propuesta que trata de ser reveladora, en el sentido de poner en evidencia, como lo hace el Cristo del evangelio, los ritos y formas que definen y dan vida a la violencia en un sentido moderno. Esto es, propone la identificación y análisis de una de las posibles fuentes de violencia en los conflictos sociales.

Las sociedades contemporáneas enfrentan cotidianamente fenómenos y expresiones en los que la violencia carcome las bases de la moralidad pública, en términos de Ronald Dworkin ${ }^{49}$, desde diferentes facetas y roles por medio de los cuales se desarrolla la colectividad. Entre estos, el derecho tiene un papel protagónico como herramienta de consenso y de transformación. Aquí se puso en duda su sostenibilidad cuando se identifica al derecho como ley, por cuanto muchas de las veces se trata de un proyecto ideológico de derecho mimetizado en argumentos que justifican la violencia y que se expresa por medio de la ley. Igualmente, esto es una advertencia.

En esta medida, la filosofía cuestiona el rol de la ley en la modernidad y cumple, así, un papel definitivo en la reorientación del derecho, con el propósito de regresarle su protagonismo como elemento transformador de los procesos políticos, sobre todo en contextos con escenarios de violencia que, como el colombiano, para el momento de escribir estas líneas (mayo de 2015), atraviesan un proceso de concertación y búsqueda de la paz, en los que confrontar a la víctima y victimario se hace necesario para una solución del conflicto. El aporte que hace la filosofía, como saber analítico, desde la crítica girardiana o desde la filosofía del derecho y de la indagación sobre la verdad de la que hablan Hegel y Heidegger,

49 El tema de la moral pública puede encontrarse a lo largo de toda la obra de Dworkin. No obstante para una perspectiva concreta puede consultarse: RoNALD DWORKIN, La comunidad liberal (Siglo del Hombre, Universidad de los Andes, Bogotá, 2004). Para tener otra idea de este problema, John Rawls, Teoría de la justicia, capítulo IV (Fondo de Cultura Económica, FCE, México, 1995). 
respectivamente, propone una reconsideración y una crítica a la luz de los derechos humanos, que sea constructiva en el sentido de hacer todo lo posible, desde el papel que juegan los diferentes operadores del derecho, sea legislador, juez, ejecutor o intérprete, por identificar y aislar los elementos de germen de violencia que amenazan la estabilidad de la sociedad.

Desde el entendimiento de la muerte de Cristo como una premisa teológica que es interpretada por la antropología filosófica, como la expresión del perdón y la reconciliación con el otro, esto también representa, en respuesta al interrogante sobre el papel del ser humano y su indagación sobre su ser y existencia, en el sentido que lo sugiere Heidegger, el posicionamiento y la victoria del débil e indefenso sobre cualquier forma de dominación o de materialización de la violencia. Esta visión trasciende más allá de cualquier interpretación cultural, justificación histórica o necesidad política en que aparentemente se explica el sacrificio del débil mediante una expresión de violencia que, como se advertía, trata de una violencia moderna. En la crítica a la mimesis y la necesidad de una víctima en la visión del pacificador, es la víctima siempre en desventaja, siempre en minoría, la que toma el papel protagónico por la reivindicación de los derechos humanos por medio de la verdad y la restauración del ser humano como ser. Esta es la memoria de la víctima, su dignificación y su retorno a la humanidad.

Esta es la advertencia más poderosa que se hace desde la tesis de la secularización. La no adoración de falsos ídolos, de la que habla el Texto, es el primer paso para rechazar los focos de génesis de violencia que, bajo la visión de modernidad criminal, se mimetizan en colectividades como partidos, gremios o masas que se caracterizan por la exclusión y cuyo estandarte muchas veces es la ley.

Aquí la responsabilidad de la ley como una de las fuentes más poderosas en los fenómenos de exclusión, tal como se expone con más fuerza en otros escritos que no se mencionan aquí, sin lugar a dudas, habla de la misma responsabilidad y de la invitación para hacer y ubicar al derecho en una narrativa que permita convertirlo en una herramienta de transformación de esas realidades. 


\section{BIBLIOGRAFÍA}

\section{Libros}

Blumenberg, Hans, Descripción del ser humano (Fondo de Cultura Económica, FCE, México, 2011).

Douzinas, Costas, El fin de los derechos humanos (Óscar Guardiola-Rivera, Ricardo Sanín-Restrepo \& Ómar Alonso-Medina, trads., Legis, Medellín, 2008).

Douzinas, Costas, Human Rights and Empire: The Political Philosophy of Cosmopolitanism (Routledge-Cavendish, New York, 2007).

Dworkin, Ronald, La comunidad liberal (Siglo del Hombre, Universidad de los Andes, Bogotá, 2004).

García-Arboleda, Juan Felipe, Regeneración o catástrofe: derecho penal mesiánico durante el siglo XIX en Colombia (Pontificia Universidad Javeriana, Bogotá, 2009).

Girard, RenÉ, El sacrificio (Encuentro, Madrid, 2010).

Girard, René, La violencia y lo sagrado (Anagrama, Barcelona, 1995).

GirARD, RenÉ, Literatura, mimesis y antropología (Gedisa, Barcelona, 2006).

Hegel, Georg W. F., Fenomenología del Espíritu (Abada, Madrid, 2010).

Hegel, Georg W. F., Filosofía del derecho (Biblioteca Nueva, Madrid, 2000).

Heidegger, Martin, Carta sobre el humanismo (Taurus, Madrid, 1996).

Llano, Alfonso, S. J., ¿Por qué callas, Dios mío? El sufrimiento humano a la luz de la fe católica (Intermedio, Bogotá, 2013).

Nino, Carlos Santiago, Introducción al análisis del derecho (Ariel, Madrid, 2003).

Peláez-Piedrahíta, Jorge H., S. J. Derechos Humanos: un Dios solidario (Pontificia Universidad Javeriana, Bogotá (1993).

Rawls, John, Teoría de la justicia, Fondo de Cultura Económica, FCE, México, 1995).

\section{Contribución en obras colectivas}

Collins, Robin, Girard and Atonement: An Incarnational Theory of Mimetic Participation, en Violence renounced: René Girard's Biblical Studies and Peacemaking, 132150 (William M. Swartley, ed., Pandora Press, Telford, Pennsylvania, 2000). Disponible en: http://home.messiah.edu/ rcollins/Philosophical\%20Theology/ Atonement/Swart7.rtf

Grimsrud, Tim, Scapegoating No More: Christian Pacifism and New Testament Views of Jesus' Death, en Violence renounced: René Girard's Biblical Studies and Peacemaking, 49-69 (William M. Swartley, ed., Pandora Press, Telford, Pennsylvania, 2000). 
Miller, Marlin E., Girardian Perspectives and Christian Atonement, en Violence renounced: René Girard's Biblical Studies and Peacemaking, 31-48 (William M. Swartley, ed., Pandora Press, Telford, Pennsylvania, 2000).

Swartley, Willard M., Discipleship and Imitation of Jesus/Suffering Servant: The Mimesis of New Creation, en Violence renounced: René Girard's Biblical Studies and Peacemaking, 218-245 (William M. Swartley, ed., Pandora Press, Telford, Pennsylvania, 2000).

Žıžex, SLAvoJ, The Fear of Four Words: A Modest Plea for the Hegelian Reading of Christianity, en The Monstrosity of Christ: Paradox or Dialectic?, 24-109 (Slavoj Žižek (ed.), Massachusetts Institute of Technology, MIT, Cambridge, 2009).

\section{Revistas}

Benhabib, Seyla, Otro universalismo: Sobre la unidad y diversidad de los derechos humanos, 39 Isegoría, Revista de Filosofía Moral y Política, 175-203 (2008). Disponible en: http://isegoria.revistas.csic.es/index.php/isegoria/article/view/627/628

CAGÜeÑas-Rozo, Diego, Las distancias del creer: secularización, idolatría y el pensamiento del otro, 34 Revista de Estudios Sociales, 123-134 (2009). Disponible en: http:// res.uniandes.edu.co/view.php/623/view.php

CASTRo-Rocha, João Cezar de, Historia cultural latinoamericana y teoría mimética: ¿por una poética de la emulación?, 27 Universitas Philosophica, 55, 105-121 (2010). Disponible en: http://revistas.javeriana.edu.co/index.php/vniphilosophica/ article/view/11049

GARZón, IvÁn, Argumentos laicos para una revisión de la secularización: una lectura desde los Derechos Humanos, 60 Persona y Derecho, $63-90$ (2009). Disponible en: http:// dadun.unav.edu/handle/10171/17488

Guardiola-Rivera, Óscar, Tiempo de excepción: el extraño retorno de la religión política, 39 Isegoría, Revista de Filosofía Moral y Politica, 227-237 (2008). Disponible en: http://isegoria.revistas.csic.es/index.php/isegoria/article/viewFile/630/631

Hopenhayn, Martín, Los avatares de la secularización: el sujeto en su vuelo más alto y en su caída más violenta, 8 Nómadas, 45-56. Disponible en: http://www.ucentral. edu.co/images/editorial/nomadas/docs/nomadas_8_4_los_avatares.pdf

Rivera-García, Antonio, La secularización después de Blumenberg, 11-12 Res Publica, 95-142 (2003). Disponible en: http://revistas.um.es/respublica/article/view/59241

Rivera-García, Antonio, Secularización y crítica del liberalismo moderno, 39 Isegoría, Revista de Filosofía Moral y Política, 79-100 (2008). Disponible en: isegoria. revistas.csic.es/index.php/isegoria/article/download/622/623

SAuquillo, Julián, Revolución y secularización, 39 Isegoría, Revista de Filosofía Moral y Politica, 13-18 (2008). Disponible en: http://isegoria.revistas.csic.es/index.php/ isegoria/article/viewArticle/618

Solarte-Rodríguez, Mario Roberto, Mímesis y noviolencia. Reflexiones desde la investigación y la acción, 27 Universitas Philosophica, 55, 41-66. Disponible en: http://revistas.javeriana.edu.co/index.php/vniphilosophica/article/view/11045 
Uribe, Carlos Alberto, Mimesis y paideia antropológica en Colombia, 1 Antípoda, 67-78 (2005). Disponible en: http://antipoda.uniandes.edu.co/view.php/8/index. php?id=8

Zarka, Yves Charles, Para una crítica de toda teología política, 39 Isegoría, Revista de Filosofía Moral y Política, 27-47 (2008). Disponible en: http://isegoria.revistas. csic.es/index.php/isegoria/article/viewFile/620/621 